\title{
Retrieval algorithm for atmospheric aerosols based on multi-angle viewing of ADEOS/POLDER
}

\author{
Sonoyo Mukai and Itaru Sano \\ Kinki University, Faculty of Science and Technology, 3-4-1 Kowakae, Higashi-Osaka 577-8502, Japan
}

(Received November 20, 1998; Revised August 1, 1999; Accepted September 7, 1999)

\begin{abstract}
POLDER-sensor onboard the satellite ADEOS has observed the reflected light from Earth surface-atmosphere system at multi-viewing angles. These directional measurements include significant information of scattering particles. The POLDER possesses high radiometric sensitivity and multi-channels in the visible and near infrared wavelengths, and measures polarization as well as radiance. This work intends to show that its multi-spectral and multi-directional measurements are useful to retrieve aerosol characteristics. The basic algorithm for aerosol retrieval is based on light scattering simulations of polarization field, where the heterogeneous aerosol model according to Maxwell-Garnett mixing rule is considered.

Monthly global distribution maps showing the Ångström exponent and the optical thickness of aerosols were obtained. From these aerosol maps, it can be seen that the aerosol distribution derived from POLDER radiance and polarization data coincides with that from the radiance data obtained independently from OCTS, and atmospheric aerosols exhibit certain intrinsic feature on a global and on a seasonal scale.
\end{abstract}

\section{Introduction}

It is well known that characteristics of atmospheric aerosols change greatly in temporal and regional scales. This paper focuses on retrieval algorithms for aerosol distribution using the measurements by the POLarization and Directionality of Earth Reflectance (POLDER) equipped on the ADvance Earth Observing Satellite (ADEOS). This new sensor is improved from a technical point of view. For example it possesses high radiometric sensitivity and multiple observing bands in the visible and near infrared wavelengths.

This work mainly cites aerosol retrieval by the combination of radiance and polarization data in the near-infrared wavelength given by POLDER. The POLDER measures both of radiance and polarization of reflected light from atmosphere, clouds, lands and the ocean. POLDER has twodimensional CCD array, which takes frame images along the orbital track. Furthermore POLDER has a capability of multi-angle viewing. The frame images are partially overlapped. Thus the target is observed several (up to fourteen) times with different viewing directions. This directional measurements, which is related to scattering behavior in the light scattering, involve significant information of scattering particles. It has been demonstrated that these new measurements are useful for aerosol retrieval over the land (Herman et al., 1997; Leroy et al., 1997). In this work, aerosol characteristics over the ocean are retrieved based on the POLDER's characteristic measurements.

\section{Overview of POLDER Measurements}

Directional, spatial and spectral information given by

Copy right $(\mathrm{C})$ The Society of Geomagnetism and Earth, Planetary and Space Sciences (SGEPSS); The Seismological Society of Japan; The Volcanological Society of Japan; The Geodetic Society of Japan; The Japanese Society for Planetary Sciences.
POLDER is briefly summarized in Fig. 1. The POLDER sensor is composed of a two dimensional CCD detector array which has a wide field of view of $\pm 51^{\circ}$ and $\pm 43^{\circ}$ in crosstrack and along-track directions (Deschamps et al., 1994). In addition the POLDER sequentially takes frame images along the orbital track. Therefore one target is captured several times because the several images are partially overlapped. This is a basic mechanism to perform multi-angle viewing which provides us with the light reflected from up to 14 directions by one target. The POLDER has eight spectral bands from visible to near infrared wavelengths, whose central wavelengths are $0.443,0.490,0.565,0.670,0.763,0.765$, 0.865 , and $0.910 \mu \mathrm{m}$. Polarized components are measured using three different polarization angles at wavelengths of $0.443,0.670$, and $0.865 \mu \mathrm{m}$. The polarization information precisely provides the aerosol characteristics. These multispectral and multi-directional measurements provide us with valuable information of aerosols.

Figure 2 presents the images of radiance and degree of polarization at a wavelength of $0.865 \mu$ m observed by POLDER on April 26 in 1997 around Japan, where each number of image corresponds to each number of viewing direction shown in the upper illustration in Fig. 1. Note that, in Fig. 2, the degree of polarization is defined as a ratio of the polarization component to the radiance in an unit of percent, and lands and clouds are painted by black. The values increase from black to white. We found that radiance images around a specular angle contain the high bright areas occurred by sun glint effect (refer to \#3 and \#7). But these sun glitter patterns are disappeared in different viewing angles away from the specular point (see \#11). Thus it is possible not only to refer to a great deal of directional information but also to avoid the sun glitter by using multi-angle viewing data.

Figure 3 shows the maximum value (an upper bunch of 


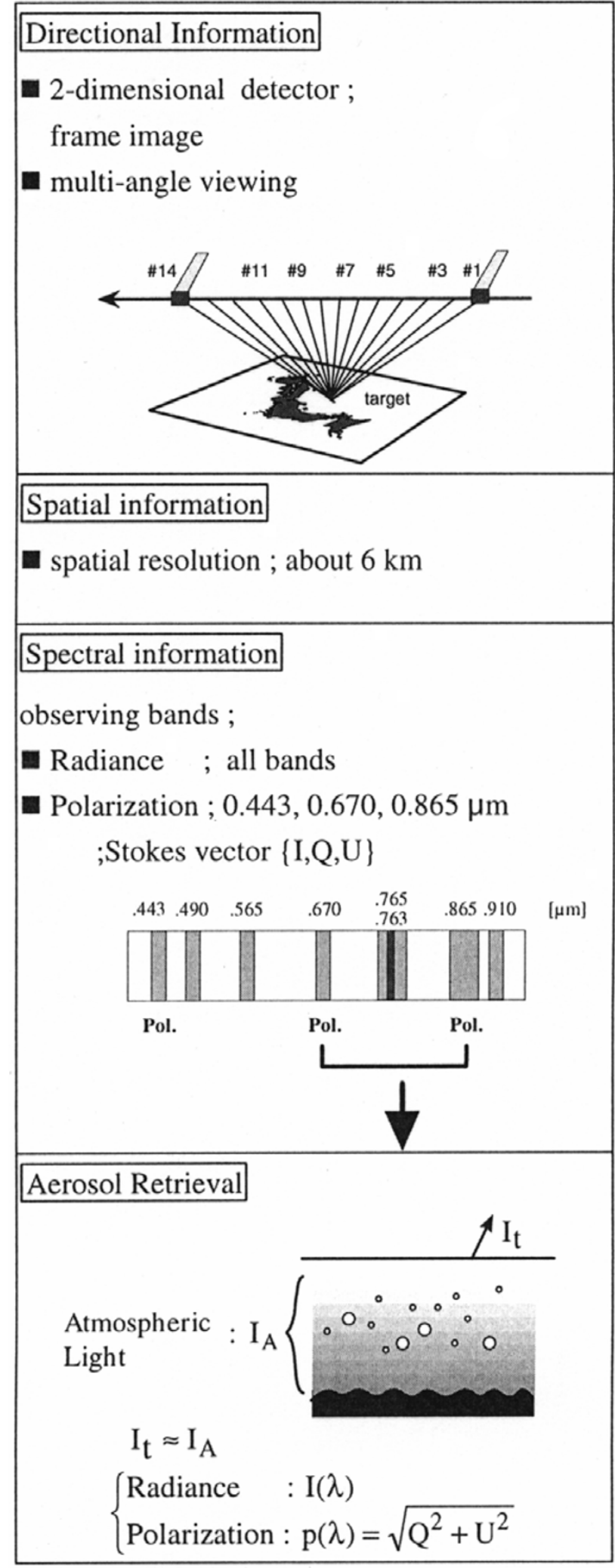

Fig. 1. Observational functions and information provided by POLDER

curves) and the minimum value (a lower one) of available scattering angles (denoted by $\Theta$ ) versus longitude acquired on one pass by POLDER on April 26, 1997, for latitudes $45^{\circ} \mathrm{N}, 40^{\circ} \mathrm{N}, 35^{\circ} \mathrm{N}$, and $30^{\circ} \mathrm{N}$ over the Japanese island, of which positions are indicated in a map. We found that
POLDER image is distributing around a scattering angle of $140^{\circ}$, and the maximum discrepancy of $\Theta$ is about $60^{\circ}$ at the same observational site (Leroy et al., 1997). Namely POLDER images are composed of back scattered light covered with wide range of scattering angles. It is shown that the multi-angle viewing provides a great deal of directional information (Martonchik and Diner, 1992).

\section{Light Scattering Simulations}

Retrieval algorithm of aerosol characteristics is based on comparison between scattering simulations and POLDERmeasurements with multi-angular viewing. In this work the radiance and polarization measurements at wavelengths of 0.670 and $0.865 \mu \mathrm{m}$ are used for aerosol retrieval. In general the contribution of radiation from the ocean to total radiation observed by satellite is negligibly small in the near infrared wavelength. In addition, the contribution of gas absorption is small at the wavelengths of $0.670 \mu \mathrm{m}$ and $0.865 \mu \mathrm{m}$ in comparison with that at $0.765 \mu \mathrm{m}$, where $\mathrm{O}_{2} \mathrm{~A}$-band absorption is too dominant to neglect. Therefore it is possible to assume that $0.670 \mu \mathrm{m}$ and $0.865 \mu \mathrm{m}$-images approximately represent the reflectance from an atmosphere-sea surface radiative model. Therefore our algorithm for aerosol retrieval is based on multiple scattering and/or reflection simulations in an atmosphere-sea surface system, (refer to the bottom illustration in Fig. 1). In Fig. 1, the specific intensity $I$ is represented by Stokes parameters $\{I, Q, U, V\}$, and $I_{\mathrm{t}}$ represents the observed radiance by the satellite, and $I_{\mathrm{A}}$ denotes the upward intensity at the top of the atmosphere derived from the light scattering calculations mentioned above, what one calls atmospheric light.

Specifically, different viewing angles of Sun and satellite on each pixel of the image correspond to light from different angles of incidence to different angles of scattering as far as the light scattering process at the particle is concerned. In other words, each pixel of the image gives each scattering angle, and intensity of atmospheric light can be calculated for an arbitrary scattering angle. Thus a scattering angle correlates radiance of a pixel of the image with a numerical value of scattering simulation for an atmosphere-sea surface model.

An inhomogeneous plane-parallel atmosphere is simulated by four homogeneous sublayers $(0-5,5-13,13-25$, $25-100 \mathrm{~km})$. The sea surface is simulated by multiple facets whose slopes vary according to the isotropic Gaussian distribution with respect to wind speed (Cox and Munk, 1955). Wind speed is assumed to be $5 \mathrm{~m} / \mathrm{sec}$ as a typical value of clear day.

Radiative transfer problem for this atmosphere-sea surface system is solved by adding-doubling method.

\section{Aerosol Distribution}

Such two components as aerosols and molecular gases are taken into account for atmospheric constituents. Since the concentration and optical properties of molecular gases are usually fixed, the radiance data in the near infrared wavelength are available to retrieve aerosol characteristics, e.g., size and composition. The optical thickness $\tau_{g}$ of the Rayleigh scattering constituents and absorbent constituents such as ozone, water vapor and oxygen molecules are ob- 


\section{Radiance Polarization}

\section{\#3}
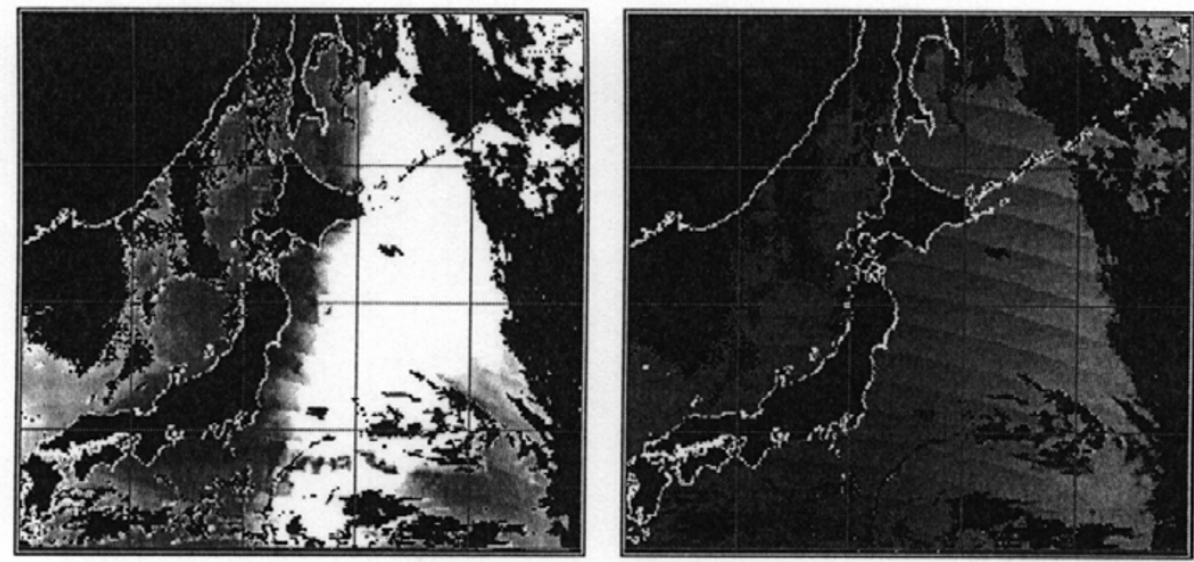

\#7
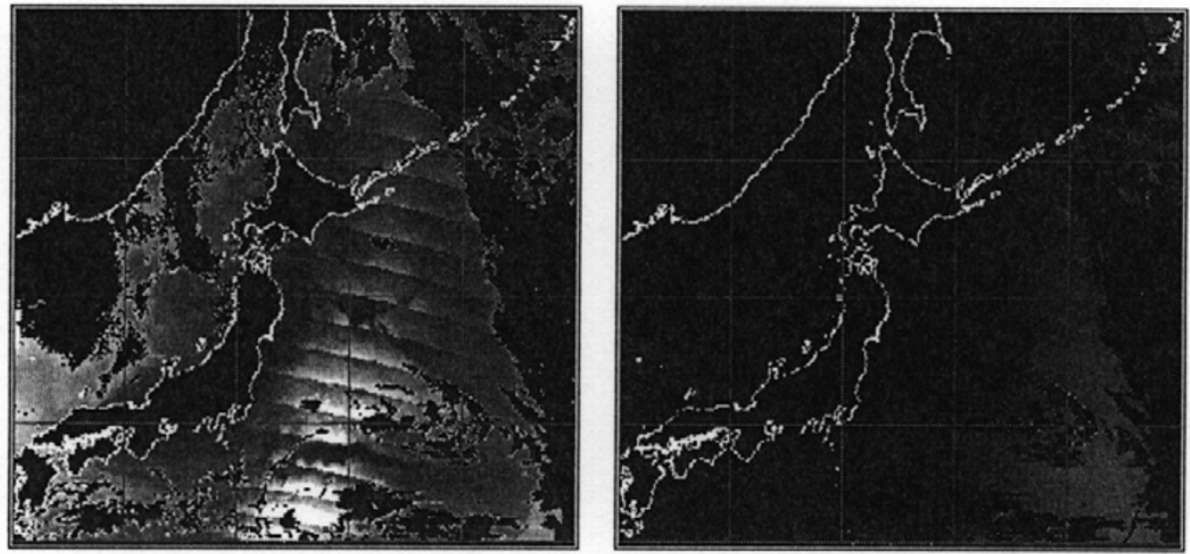

\#11
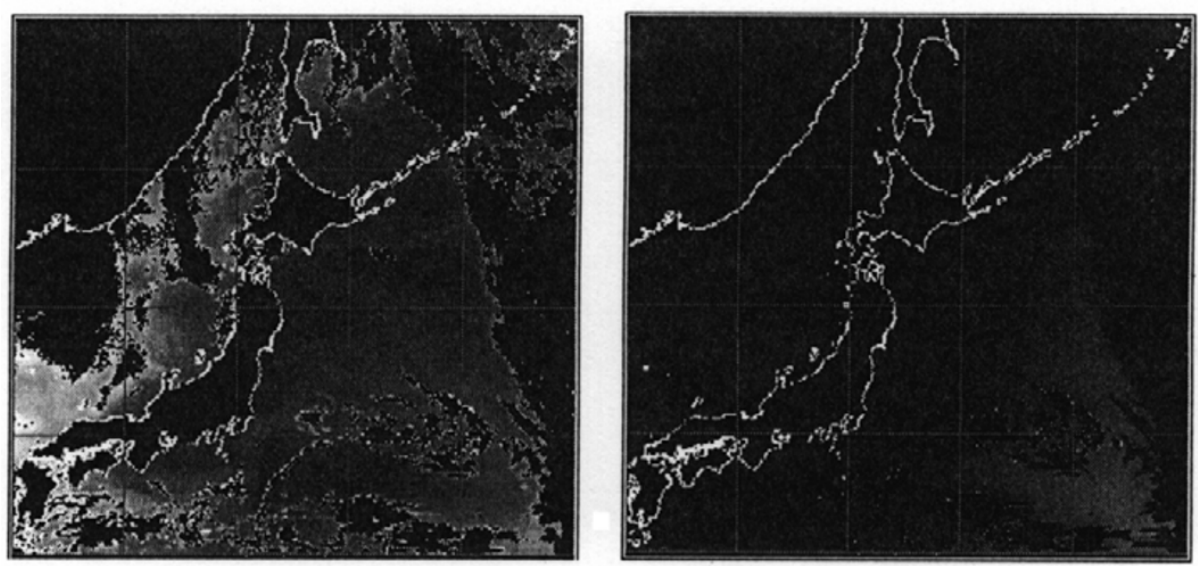

Fig. 2. Radiance and degree of polarization at a wavelength of $0.865 \mu \mathrm{m}$ observed by POLDER on April 26 in 1997 around Japan, where each number of image corresponds to each number of viewing direction shown in the upper illustration in Fig. 1.

tained by LOWTRAN 7 (Kneizys et al., 1988). The single scattering phase matrix in our atmosphere model is expressed with the following form;

$$
P(\Theta)=\left(1-f_{g}\right) P_{a}(\Theta)+f_{g} P_{g}(\Theta),
$$

where $\Theta$ is the scattering angle and subscripts $a$ and $g$ denote aerosols and molecular gases respectively. The matrices $P_{a}$ and $P_{g}$, respectively, are given by Mie scattering phase matrix if an aerosol model is fixed, and by the Rayleigh phase matrix. The value of $f_{g}$ represents the ratio of the opacity source by molecules to the total one.

$$
f_{g}=\tau_{g} /\left(\tau_{g}+\tau_{a}\right),
$$

where $\tau_{a}$ represents the aerosol optical thickness. This value is one parameter to be retrieved in our simulations. 

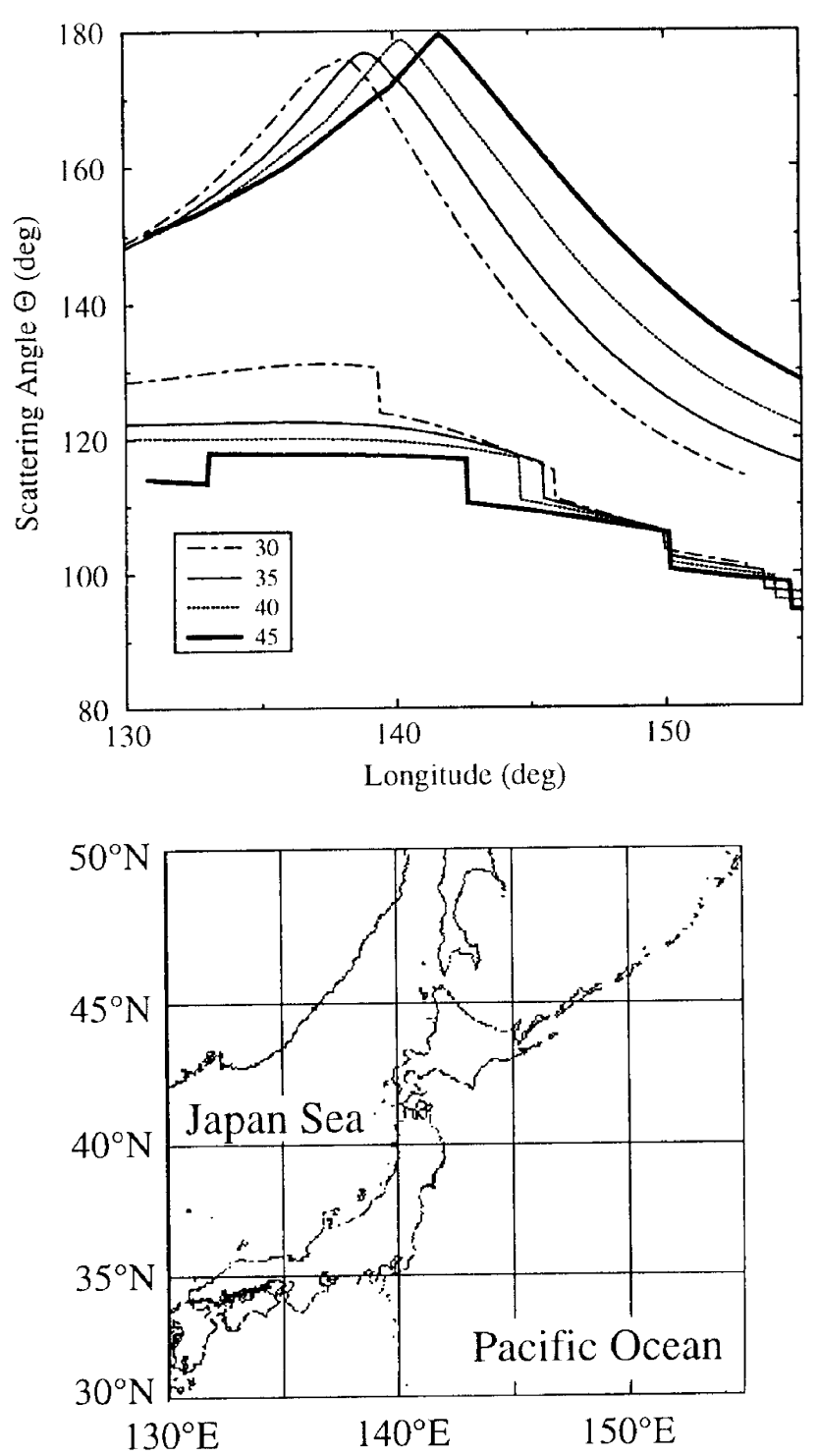

Fig. 3. Range of available scattering angles vs longitude acquired on one pass by POLDER on April 26, 1997, for latitudes $45^{\circ} \mathrm{N}, 40^{\circ} \mathrm{N}, 35^{\circ} \mathrm{N}$, and $30^{\circ} \mathrm{N}$, which is indicated in a map.

A single-mode log-normal representation with two parameters, the modal radius $(\bar{r})$ and the width of the log-normal curve $(\sigma)$, is considered here for one of the most widely used size distributions.

$$
\frac{d N(r)}{d r}=\left(\frac{C}{\sqrt{2 \pi} r \ln \sigma}\right) \exp \left[-\frac{(\ln r-\ln \bar{r})^{2}}{2 \ln ^{2} \sigma}\right],
$$

where $d N(r) / d r$ is the number of particles whose radii are between $r$ and $r+d r$ and $C$ is the total concentration. Thus it becomes our purpose to retrieve $(\bar{r}, \sigma)$ for the log-normal distribution. However, for the sake of simplicity, $\sigma$ is fixed at 2.2 in the present calculations. Finally aerosol optical thickness $\left(\tau_{a}(0.5)\right)$ at a wavelength of $0.5 \mu \mathrm{m}$ and Ångström exponent $(\alpha)$ are employed as the retrieved parameters for the comparison and validation of our results (Goloub et al., 1999; Nakajima et al., 1999).

It is natural to consider that several kinds of aerosols could exist together in general. Here we take into account heterogeneous particles for maritime aerosol models. World
Meteorological Organization (World Climate Program-112, 1986) and d'Almeida et al. (1991) have proposed the typical aerosol models. These aerosol models are mixed with several components, e.g., maritime aerosols are mainly composed of oceanic component and water-soluble one. In this work, we adopt Maxwell-Garnett theory (Bohren and Wickramasinghe, 1977; Chýlek and Srivastava, 1983) as the heterogeneous aerosol particle. Maxwell-Garnett rule treat with di-electric constants, which relate to the complex refractive indices. Water soluble component and oceanic component are considered for inclusions and matrix, respectively. The refractive indices for a heterogeneous particle shows a proportional allotment to the volume fraction of inclusions to the matrix (Sano et al., 1997).

We can choose the best candidate for atmospheric aerosols such that a simulated result most excellently suits to the multiangle measurements on each pixel of POLDER image. The error is evaluated in terms of the extent to which the simulated values deviate from the observed data as follows;

$$
\begin{aligned}
& \text { Error } I=\frac{1}{2 N_{d i r}}\left[\sum_{\text {dir }=1}^{N_{d i r}} \sum_{\lambda=1}^{2}\left|\frac{O b s I_{\lambda, d i r}-\operatorname{Sim} I_{\lambda, d i r}}{O b s I_{\lambda, d i r}}\right|\right], \\
& \text { Error_P }=\frac{1}{2 N_{d i r}}\left[\sum_{d i r=1}^{N_{d i r}} \sum_{\lambda=1}^{2}\left|\frac{O b s \_P_{\lambda, d i r}-\operatorname{Sim} P_{\lambda, d i r}}{O b s \_P_{\lambda, d i r}}\right|\right],
\end{aligned}
$$

Total error $=($ Error $I+$ Error $P) / 2$,

where $O b s$ and Sim represent observational data and simulated results stored in the look up table, respectively. The symbol $I$ and $P$ represent the total radiance and degree of polarization. $\lambda$ and $d i r$ denote the number of wavelength and directional data sets. An aerosol model that results in the minimum value for total error in Eq. (6) is selected as the best candidate at each pixel. Note that the pixel with this minimum value over ten percent is abandoned.

Figure 4 presents the diagram how to retrieve aerosol parameters based on the comparison of simulations with POLDER data. In Fig. 4 values of Angström exponent and aerosol optical thickness at a wavelength of $0.5 \mu \mathrm{m}$ and Ångström exponent are denoted by the solid and dashed curves, respectively, and POLDER radiance and/or polarization data are indicated by dots at wavelengths of $0.670 \mu \mathrm{m}$ and $0.865 \mu \mathrm{m}$. Each number of image in Fig. 4 roughly corresponds to each number of viewing direction shown in the illustration of Fig. 1. It is self-evident that aerosol retrieval will be not evident, if observations are undertaken at one direction alone. Because several simulated results with their own aerosol model are possible to interpret an observed data of one direction. The result is that there are several feasible solutions for retrieval problem of aerosol by using one directional data alone. Therefore we need additional condition in order to get a unique solution. POLDER-multi-angle data, which provides the directional distribution of radiance and polarization, can solve this ambiguous problem. Thus both the spectral and directional information of the radiance and polarization are used to retrieve aerosol parameters at each pixel of the image, i.e., aerosol distribution over the whole image.

Figure 5 shows the retrieved distribution of $\tau_{a}(0.5)$ (left- 


\section{Reflectance}

\section{\# 7}

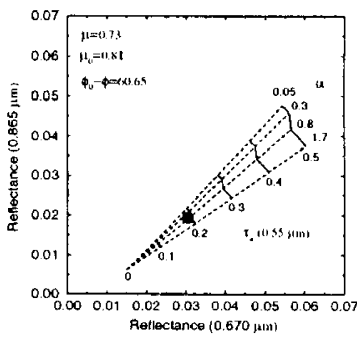

\#10

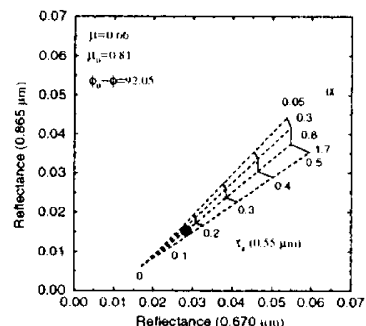

\# 8

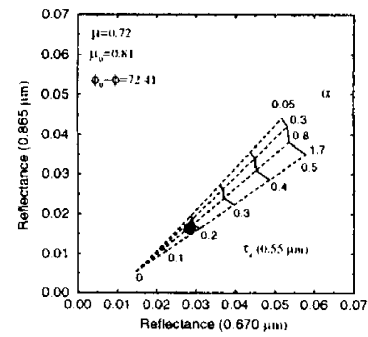

\#11

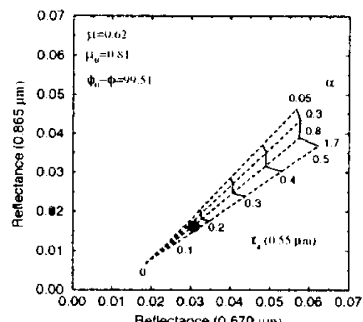

\# 9

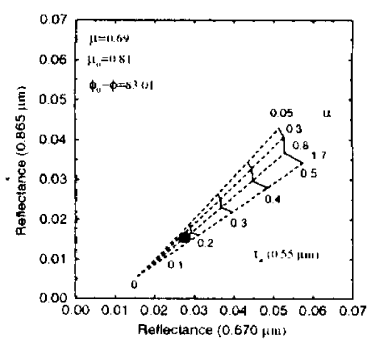

\#12

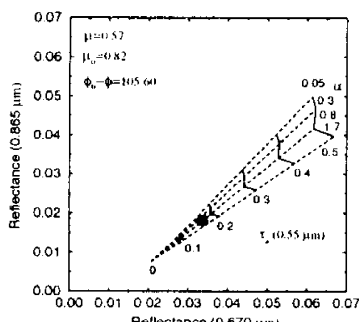

\section{Degree of Polarization}

\# 7

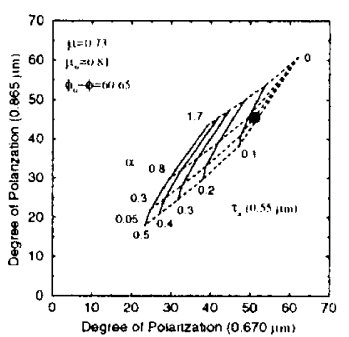

\#10

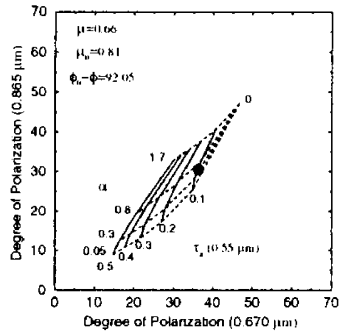

\# 8

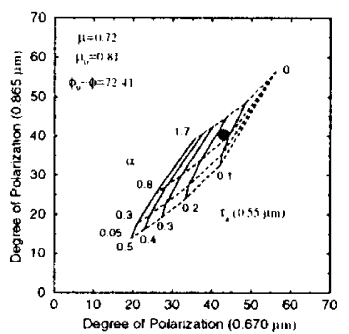

\# 11

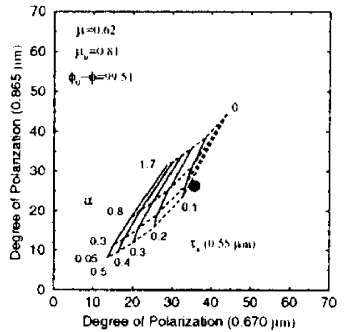

\# 9

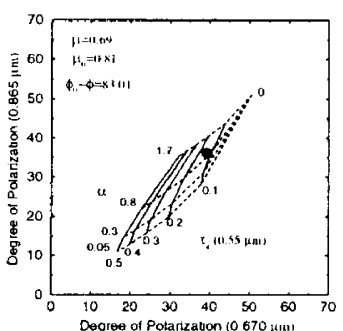

\section{\#12}

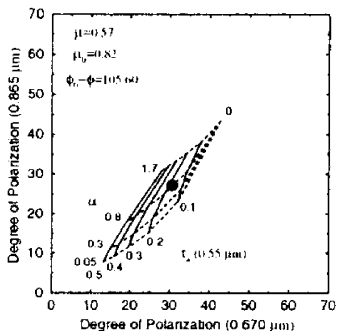

Fig. 4. Relationship between $\alpha$ and $\tau_{a}(0.5)$ for the radiance (upper figures) and polarization degree (lower figures) at wavelengths of $0.670 \mu \mathrm{m}$ and 0.865 $\mu \mathrm{m}$. POLDER data is indicated by dots and each number above the each image roughly corresponds to each viewing direction shown in the illustration of Fig. 1. 


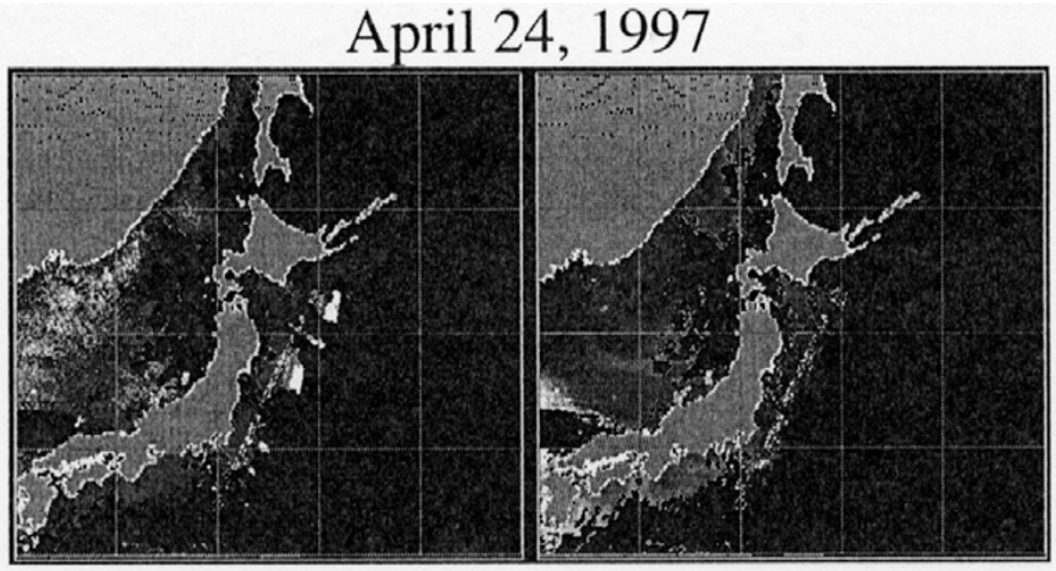

\section{April 25, 1997}

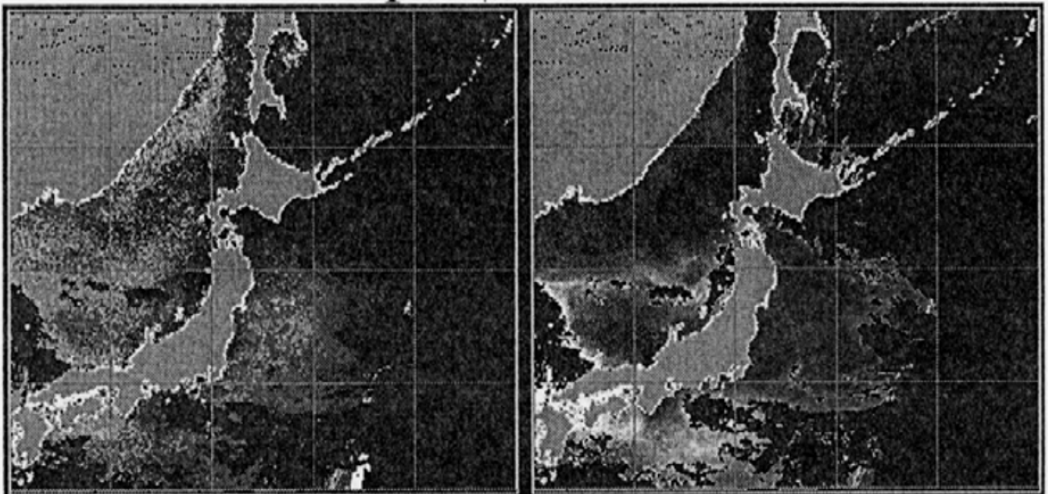

April 26, 1997
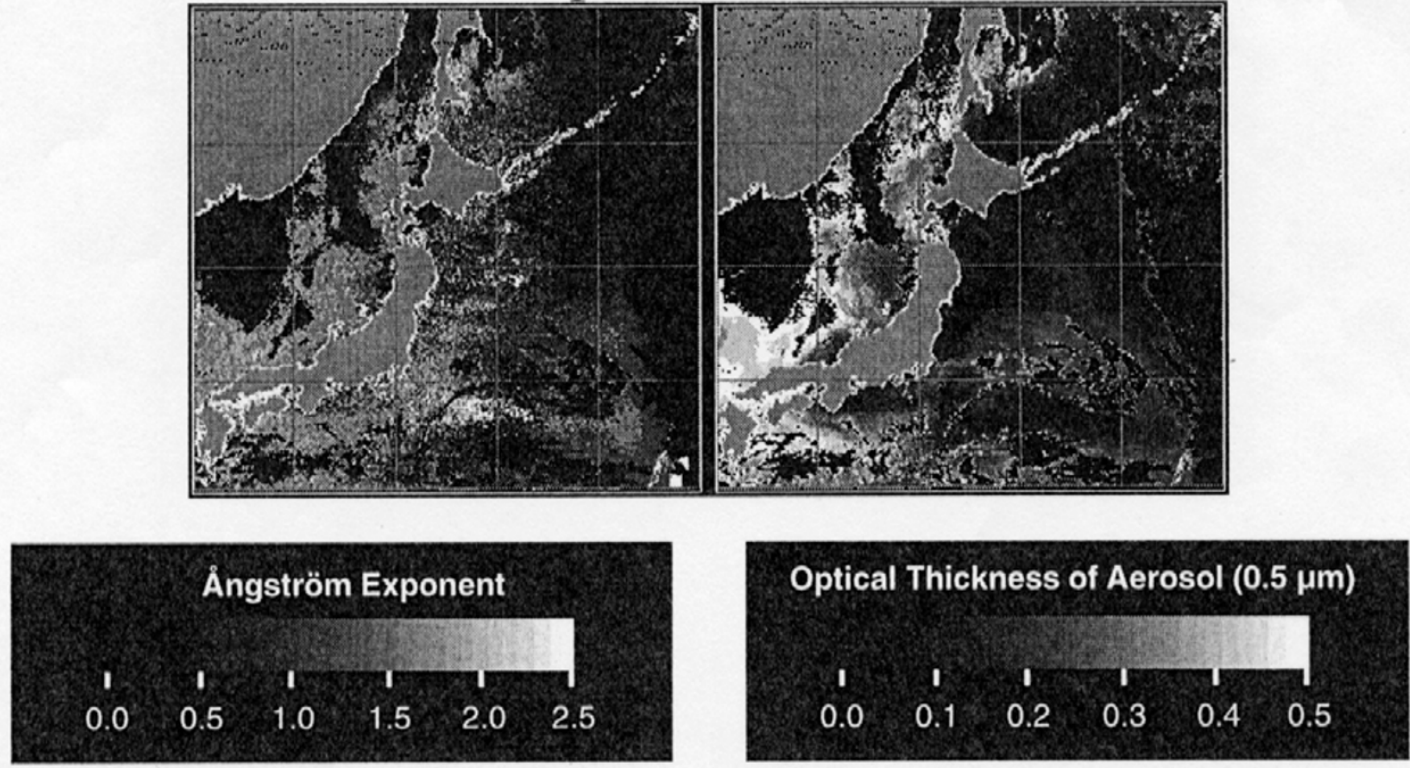

Fig. 5. Local distribution of $\alpha$ (left) and $\tau_{a}(0.5)$ (right) around Japan on April 24, 25, 26 in 1997.

hand side) and $\alpha$ (right-hand side) on April 24, 25 and 26 in 1997. The low aerosol optical thickness region is seen to correspond to the low Ångström exponent. This result suggests existence of coarse mode aerosol. On the other hand, high values for $\tau_{a}$ and $\alpha$ indicate a concentration of small aerosols, which originate in the interior of East Asia.
It is also clearly apparent that the characteristic pattern of aerosols movement is from west to east in accordance with prevailing winds and weather changes.

Global distribution is derived from all of the data obtained throughout a one-month period over the whole world. Figure 6 shows the distribution of $\tau_{a}(0.5)$ and $\alpha$ in November, 
November, 1996
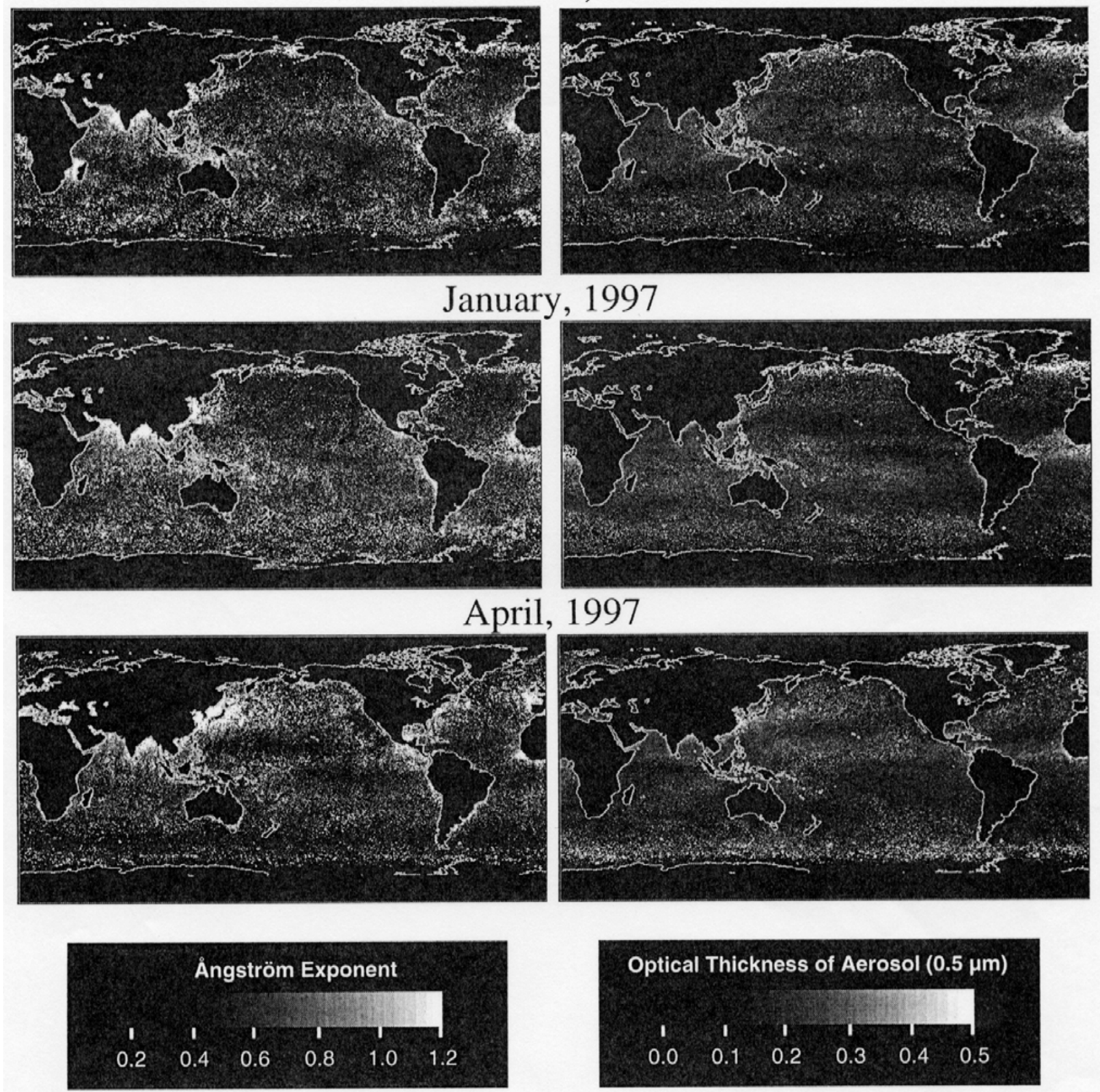

Fig. 6. Global distribution of $\tau_{a}(0.5)$ and $\alpha$ in November 1996, January 1997 and April 1997.

1996 and in January and April, 1997. Our results coincide with the aerosol map derived from OCTS radiance data by Nakajima et al. (1999). It is interesting to note that these global distributions represent several characteristic pattern of aerosols on a world-wide scale. Husar (Husar et al., 1997) mentioned that a high concentration of aerosols is seen over the Gulf of Guinea throughout the year. These aerosols seem to be dust-originated particles from the Sahara desert. Our results also indicate large values of $\tau_{a}$ over the Gulf of Guinea for all three months in this study. However, data for April 1997 shows relatively little aerosol loading (Nakajima et al., 1999). This phenomenon has been interpreted as due to a reduction in dust generation in the desert. It is also seen that continental aerosols flow into the air over the Arabian sea and Bay of Bengal near India due to the northeast monsoon in winter. In contrast, the atmosphere of East Asia around Japan contains lots of aerosols in April. This region experiences dust aerosols originated from the Gobi desert in the early spring, which is referred to as the Kosa (yellow dust) phenomenon. From another viewpoint, we can say that small aerosols are found in the coastal regions near major urban areas such as the east coast of China, Japan, the east coast of North America and around Europe. These aerosols seem to be generated artificially. Asia, in particular, is a major source of anthropogenic sulfur and nitrogen emissions as well as the source of biomass burning products (Husar et 
al., 1997). These products are transported to the West and Central Pacific Ocean due to the typical monsoon patterns in the winter and early spring.

\section{Conclusions}

It has been shown that the distributions of local daily and global monthly aerosol optical thickness and Ångström exponent can be successfully obtained using POLDER's characteristic data. Our global distribution of aerosols in April 1997 generally coincides with that proposed by Nakajima (Nakajima et al., 1999), which is derived based on a different algorithm using ADEOS/OCTS radiance data only. It can be said that this general agreement of results validates our procedure because ADEOS/OCTS and POLDER were used to simultaneously observe the same target.

In summary the present study found that efficient aerosol retrieval has been made based on the multi-angle/-spectral measurements and a combination of radiance and polarization data (Mischenko and Travis, 1997).

Acknowledgments. The results were obtained from CNES's POLDER installed on NASDA's ADEOS. The authors are very grateful to Drs. Marc Leroy and Kazuhiko Masuda for their careful reading of our manuscript and valuable comments.

\section{References}

Bohren, C. F. and N. C. Wickramasinghe, On the computation of optical properties of heterogeneous grains, Astrophys. Space Sci., 50, 461-472, 1977.

Chýlek, P. and V. Srivastava, Dielectric constant of a composite inhomogeneous medium, Phys. Rev. B, 27, 5098-5106, 1983.

Cox, C. and W. Munk, Some problems in optical oceanography, J. Mar. Res., 14, 63-78, 1955.

d'Almeida, G. A., P. Koepke, and E. P. Shettle, Atmospheric AerosolsGlobal Climatology and Radiative Characteristics, 561 pp., Deepak Pub., Hampton, VA, 1991.
Deschamps, P. Y., F.-M. Bréon, M. Leroy, A. Podarie, A. Bricaud, J. C. Buriez, and G. Sèze, The POLDER mission: Instrument characteristics and scientific objectives, IEEE Trans. Geosci. Remote Sensing, 32, 598615, 1994.

Goloub, P., D. Tanré, J. L. Deuzé, M. Herman, A. Marchand, and F. M. Bréon, Validation of the first algorithm applied for deriving the aerosol properties over the ocean using the polder/adeos measurements, IEEE Trans. Geosci. Remote Sensing, 37, 1586-1596, 1999.

Herman, M., J. L. Deuzé, C. Devaux, P. Goloub, F. M. Bréon, and D. Tanré, Remote sensing of aerosols over land surfaces including polarization measurements and application to POLDER measurements, J. Geophys. Res., 102, 17039-17049, 1997.

Husar, R. B., J. M. Prospero, and L. L. Stowe, Characterization of tropospheric aerosols over the oceans with the NOAA advanced high resolution radiometer optical thickness operational product, J. Geophys. Res., 102 16889-16909, 1997.

Kneizys, F. X., E. P. Shettle, L. W. Abreu, J. H. Chetwynd, G. P. Anderson, W. O. Gallery, J. E. A. Selby, and S. A. Clough, Users Guide to LOWTRAN 7, 90 pp., AFGL-TR-88-0177, Air Force Geophysics Laboratory, Hanscom AFB. MA, 1988.

Leroy, M., J. L. Deuzé, F. M. Bréon, O. Hautecoeur, M. Herman, J. C. Buriez, D. Tanré, S. Bouffiès, P. Chazette, and J. L. Roujean, Retrieval of atmospheric properties and surface bidirectional reflectances over land from POLDER/ADEOS, J. Geophys. Res., 102, 17023-17037, 1997.

Martonchik, J. V. and D. J. Diner, Retrieval of aerosol optical properties from multi-angle satellite imagery, IEEE Trans. Geosci. Remote Sensing, 30, 223-230, 1992.

Mischenko, M. I. and L. D. Travis, Satellite retrieval of aerosol properties over the ocean using polarization as well as intensity of reflected sunlight, J. Geophys. Res., 102, 16989-17013, 1997.

Nakajima, T., A. Higurashi, K. Aoki, T. Endoh, H. Fukushima, M. Toratani, Y. Mitomi, B. G. Mitchell, and R. Froui, Early phase analysis of octs radiance data for aerosol remote sensing, IEEE Trans. Geosci. Remote Sensing, 37, 1575-1585, 1999.

Sano, I., S. Mukai, and T. Takashima, Polarimetric properties of atmospheric aerosols, in Proc. SPIE '97, 3121, pp. 361-369, 1997.

World Climate Program, WCP-112, A preliminary Cloudless Standard Atmosphere for Radiation Computation, 112 pp., WMO/TD-No. 24, World Meteorological Organization, Geneva, 1986.

S. Mukai (e-mail: mukai@im.kindai.ac.jp) and I. Sano 